\title{
EUGENESIA Y AUTORÍA MORAL. LECTURA DE UNA TESIS HABERMASIANA
}

\author{
CÉSAR ORTEGA ESQUEMBRE \\ Universidad de Valencia
}

\begin{abstract}
RESUMEN. el objetivo de esta comunicación es ahondar en la visión que ha mantenido Jürgen Habermas a propósito de la manipulación genética; en concreto, se pretende abordar críticamente su hipótesis de una pérdida de autoría del sujeto manipulado. A juicio del autor, la intervención genética positiva - aquélla que tiene por objeto la introducción de virtuales mejoras en el sujeto- alcanzaría a violar la conciencia de autoría de dicho sujeto, así como su autocomprensión en tanto agente moral. En este sentido, se pretende investigar críticamente dos aspectos diferentes de la cuestión: en primer lugar, la corrección o no de la tesis habermasiana; en segundo lugar, la pertinencia o no de dicha tesis a la hora de oponerse a una generalización de la eugenesia positiva: ¿existen argumentos distintos, dentro del propio marco conceptual habermasiano, para oponerse a tal generalización?
\end{abstract}

PALABRAS CLAVE: eugenesia, autonomía, moral.

\section{Eugenics and moral authorship. Analysis of a Habermas's thesis}

ABSTRACT- the aim of this paper is to study the Jürgen Habermas's vision of genetic manipulation; in particular, it will be addressed critically his assumption that the genetically engineered person would loose his awareness of authorship. In the author's view, positive genetic intervention -one that is to genetically enhance the subject - would eliminate the awareness of authorship of that subject, as well as his self-understanding as moral agent. Two aspects of the question will be approached: firstly, the correctness or incorrectness of Habermas's thesis. Secondly, the relevance of the thesis to oppose positive eugenics. Could be other arguments considered within Habermas's conceptual framework to oppose positive eugenics?

KEY WORDS: eugenics, autonomy, moral.

Mediante esta comunicación pretendo abordar críticamente una de las tesis que Jürgen Habermas defendiera en su ahora célebre texto de 2001 El futuro de la naturaleza humana, ¿hacia una eugenesia liberal? ${ }^{1}$ Aunque las controversias a que ha dado lugar dicho texto son ciertamente variadas, voy a centrarme directamente en la parte de la argumentación habermasiana que me gustaría someter a examen crítico.

A mi modo de ver, el texto de Habermas expone al menos tres cuestiones clínicas fundamentales que tienen consecuencias de tipo moral. En primer lugar, el diagnóstico genético preimplantacional, es decir, la posibilidad de someter a prueba genética a los embriones fecundados in vitro, con la intención de seleccionar para su

1 Habermas, J., El futuro de la naturaleza humana. ¿Hacia una eugenesia liberal?, Paidós, Barcelona, 2002. 
implantación sólo aquéllos que no posean la enfermedad monogenética hereditaria que, dada la genética de los padres, es probable suponer que poseerán. En segundo lugar, la eugenesia negativa, es decir, una modificación genética terapéutica que tiene por objeto evitar enfermedades hereditarias. En tercer lugar, la eugenesia positiva, es decir, la utilización de la técnica genética con el objetivo de perfeccionar determinados rasgos de la futura persona. Antes de comenzar con el análisis, quizás resulte interesante mencionar que son muchos y variados los posibles modos de intervención genética. Buchanan, Brock, Daniels y Wikler han diferenciado tres vías fundamentales: una directa, en la que cabría tanto la terapia génica, «en la que se insertan genes deseables» en las células o en los embriones, como la cirugía genética, en la que se "desactivan» genes que producirían efectos adversos; otra indirecta, donde entrarían tanto la farmacología genética como la selección de embriones, tras cuyo análisis se implanta sólo el más deseable —éste es el mencionado diagnóstico genético preimplantacional—; y una tercera vía menos directa, la del diagnóstico genético prenatal ${ }^{2}$.

Aunque cada una de estas cuestiones presenta problemas normativos específicos, nosotros vamos a centrarnos exclusivamente en la argumentación filosófica que realiza Habermas para oponerse a la eugenesia perfeccionadora —eugenesia que, por lo demás, sería hoy estructurada bajo los parámetros liberales de la oferta y la demanda ${ }^{3}$.

Resumo muy brevemente la argumentación al respecto. A juicio de Habermas, la manipulación genética con fines perfeccionadores tendría dos consecuencias adversas conectadas entre sí. En primer lugar, la disposición técnica de lo hasta este momento indisponible, es decir, de la herencia genética, y por tanto la instrumentalizadora desdiferenciación entre lo producido y lo sido por naturaleza, que Habermas llama "tecnificación de la naturaleza humana» ${ }^{4}$, alcanzaría a modificar nuestra propia autocomprensión ética como especie, compartida por todos los seres humanos. Esta autocomprensión se basa en las condiciones de lo espontáneamente natural, que, dice literalmente Habermas, «constituye lo único en lo que podemos entendernos como autores de la propia vida y miembros en pie de igualdad de la comunidad moral» ${ }^{5}$. Este fenómeno da lugar a la segunda consecuencia adversa. Modificar la autocomprensión ética de la especie socavaría a su vez nuestra autocomprensión moral, que se basa en aquélla. Tras conocer que se ha intervenido en su herencia genética con fines no terapéuticos, tal es la argumentación de Habermas, el adolescente experimentará su cuerpo (Leib) como algo hecho, y en tal medida dejará de saberse autor último de su propia biografía. Este cambio de conciencia, esta autopercepción objetivante, terminará por modificar nuestra comprensión como seres autónomos, libres e iguales. Con la destrucción

\footnotetext{
2 Buchanan, A.; Brock, D.W.; Daniels, N. y Wikler, D., Genética y justicia, Cambridge University Press, Madrid, 2002, pp. 5-7.

3 Para un estudio de la problemática entre eugenesia y justicia social, véase SiNGER, P., «De compras por el supermercado genético» en: Isegoría, 27, 2002, pp. 19-40; BuchanAn, A.; Brock, D.W.; Daniels, N. y Wikler, D., Genética y justicia. Op. Cit.

4 Habermas, J., El futuro de la naturaleza humana. Op. Cit., p. 38.

5 Ibid., 62.
} 
de la conciencia de autoría quedan igualmente rotos los fundamentos normativos de la moral y el derecho universalistas.

Nos sabemos sujetos morales en la medida en que actuamos y juzgamos in propia persona, es decir, «en que por nosotros no habla ninguna otra voz más que la propia» ${ }^{6}$. Justamente este "poder ser sí mismo» es el que, a juicio del autor, queda perturbado con la «intención ajena» introducida en nuestra biografía mediante la programación genética. La programación, por así decirlo, fija irreversiblemente a la persona afectada a un plan de vida concreto de acuerdo con las intenciones de un tercero. Este plan de vida, caso de que posteriormente fuera rechazado, no podría ya ser retrospectivamente revisado por el adulto, que de esta forma dejaría de entenderse a sí mismo como autor de su propia vida.

Expuesta así la argumentación habermasiana, voy a formular brevemente mi comentario crítico. Estoy de acuerdo con Habermas en dos partes fundamentales de la argumentación, pero discrepo en una tercera. Estoy de acuerdo, en primer lugar, en que una modificación de la autocomprensión ética de la especie, en el sentido de que el ser humano deje de verse a sí mismo como autor autónomo y libre de su propia vida, ha de terminar necesariamente por socavar los fundamentos de la comunidad moral. En efecto, la comunidad moral se fundamenta, según la propia teoría de Habermas, en la autónoma capacidad de cada sujeto para asentir o rechazar ante las pretensiones normativas de validez del resto de personas ${ }^{7}$. Tan pronto como los participantes en el discurso fundamentador de normas no actuaran conforme a sus propias convicciones —esto es, autónomamente- la estructura misma de la moral quedaría cancelada.

En segundo lugar, también estoy de acuerdo con Habermas en la conclusión a que llega, es decir, en el rechazo a la eugenesia perfeccionadora. Sin embargo, y en tercer lugar, discrepo con él en la primera de las premisas que le llevan a esta conclusión, a saber, que la programación genética ha de modificar nuestra autocomprensión ética de la especie, en el sentido de una pérdida de la conciencia de autoría. No veo en qué sentido la manipulación genética positiva modificaría dicha autocomprensión ética. ¿Por qué la persona modificada va a sentirse menos autor de su vida que la persona naturalmente determinada? O dicho de otra forma, ¿por qué el hecho de sustituir el azar por la intervención intencionada cancela la conciencia de autoría? Adela Cortina ha formulado esta inquietud en los siguientes términos: "no parece que el descubrimiento de que en su caso la lotería natural se haya reducido lleve a una persona a perder la capacidad de regirse por leyes universalizables o de dirigir su vida por sí misma desde el reconocimiento mutuo. Nadie elige nacer, y ése no es un obstáculo a la autonomía» ${ }^{8}$.

Y sin embargo creo que cabe encontrar en la propia argumentación de Habermas una tesis mejor para oponerse a la eugenesia positiva. La modificación genética con fines no terapéuticos adopta una actitud instrumentalizadora con el embrión. Si sustituimos esta actitud por una acción comunicativa, según la propia teoría de

Ibid., 80 .

7 Para un estudio detallado de la fundamentación teórico-moral habermasiana véase HABERMAS, J., Conciencia moral y acción comunicativa, Trotta, Madrid, 2008, cap. III; HABERMAS, J., Aclaraciones a la ética del discurso, Trotta, Madrid, 2000, Cap. VI.

8 CortinA, A., «Ética de las biotecnologías» en Isegoría, 27, 2002, pp. 73-89. 
Habermas, se observa bien cómo la imposibilidad de garantizar un futuro consenso con el interlocutor virtual que es el propio embrión deslegitima moralmente la manipulación. Las intenciones programadoras de los padres aparecen en la biografía del niño como sustraídas «a las condiciones de reciprocidad del entendimiento comunicativo»". Los padres realizan una decisión "sin suponer el consenso, según sus propias preferencias, igual que si dispusieran de una cosa». Hasta donde yo alcanzo a comprender, éste último ya no es un argumento de ética de la especie, sino un argumento moral.

¿Por qué, en lugar de suponer que la intervención perfeccionadora afectará a la autocomprensión del sujeto como autor de su propia vida, no decir sencillamente, desde el punto de vista moral que la teoría del discurso trata de reconstruir, que no puede garantizarse un futuro consentimiento del niño con respecto a dicha intervención? Es decir, ¿por qué la anticipación de un acuerdo, o en su caso la anticipación de una negativa, no es suficiente para dirimir la problemática eugenésica? Basta en este caso con tomar al embrión como «la segunda persona que algún día sería». El propio Habermas se sirve de esta tesis en algunos momentos del texto, pero inmediatamente después vuelve a recurrir a la fórmula de la pérdida de autoría. Creo que la argumentación moral explica bien la diferente sensación con que reaccionamos a la eugenesia positiva y a la negativa. "Sólo en el caso negativo de la evitación de males muy generalmente considerados extremos existen buenas razones para aceptar que el afectado asentiría al objetivo de la eugenesia» ${ }^{10}$.

Naturalmente que para este objetivo sería preciso trazar una frontera clara entre la curación y la mejora, y esa frontera habría de ser a su vez el resultado consensuado de un diálogo en el que todos, ilustrados por la competente opinión que recae en el especialista, pudieran participar. ¿No es esa frontera en sí misma una cuestión moral? 